\title{
A despersonalização do paciente e da sua história: uma visão holística da literatura
}

\author{
Depersonalization of the patient and his \\ history: a holistic view of the literature
}

\section{Bruno Henrique Ramos Bispo' 1 (i) Débora Lopes dos Santos ${ }^{2}$ (1) Ariane Nascimento Macedo ${ }^{3}$ (1)}

\author{
1Autor para correspondência. Universidade do Estado da Bahia (Salvador). Bahia, Brasil. brunohenriqueb@live.com \\ 2Universidade do Estado da Bahia (Salvador). Bahia, Brasil. lopesdebora761@gmail.com \\ 3Universidade Federal da Bahia (Salvador). Bahia, Brasil. arianemmacedo28@gmail.com
}

RESUMO | INTRODUÇÃO: A despersonalização do paciente e de sua história está presente no cuidado e é descrita com muita sensibilidade na literatura, que, por representar o ser de maneira integral, demonstra o quanto esse processo de desumanização pode ser danoso. OBJETIVO: Este ensaio tem como propósito demonstrar o quanto a literatura pode proporcionar uma visão holística do paciente no processo de perda de autonomia. RESULTADOS: O conto Paulo, do autor Graciliano Ramos, analisa, de forma poética e subjetiva, um cenário de despersonalização do paciente e de sua história e como ele pode ser angustiante. Por outro lado, é importante analisar contextos como o profissional com síndrome de Burnout e a pandemia pela COVID-19 como potencializadoras dessa desumanização do paciente, já que estes cenários representam situações que desencadeiam estresse físico e emocional para o profissional de saúde e, portanto, podem desencadear distanciamento emocional e desumanização por parte do cuidador. CONCLUSÃO: A literatura traz subjetividade ao representar o processo de adoecimento e hospitalização sob a perspectiva do paciente e, dessa forma, permite uma visão integral do ser, que é imprescindível para minimizar a despersonalização do paciente e de sua história, nesse sentido, a análise desse contexto torna necessária a inserção de abordagens no cuidado que ultrapassem o foco no adoecimento, com a valorização da escuta e autonomia do paciente.

PALAVRAS-CHAVE: Relação médico-paciente. Educação Médica. Humanização.
ABSTRACT | BACKGROUND: The depersonalization of the patient and his/her history is present in health care and it is described with great sensitivity in the literature, which, because it represents the human being integral, demonstrates how harmful this dehumanization process can be. OBJECTIVE: This essay aims to demonstrate how much the literature can provide a holistic view of the patient in the process of loss of autonomy. RESULTS: The short story Paulo by author Graciliano Ramos analyzes, in a poetic and specific way, a scenario of depersonalization of the patient and his history and how distressing it can be. On the other hand, it is important to analyze contexts such as the professional with Burnout syndrome and the pandemic by COVID-19 as potentiating this patient's dehumanization, since these scenarios trigger physical and emotional stress for the health professional and, therefore, can trigger emotional distance and dehumanization by the caregiver. CONCLUSION: The literature brings subjectivity to represent the process of illness and hospitalization from the perspective of the patient and, thus, allows an integral view of the being, which is essential to minimize the depersonalization of the patient and his history. The analysis from this context is necessary to insert approaches in care that go beyond the focus on illness, with the appreciation of listening and patient's autonomy.

KEYWORDS: Doctor-patient relationship. Medical education. Humanization. 


\section{Introdução}

A escrita sobre a enfermidade está incluída não só na anamnese médica, mas também em diversas outras manifestações da cultura humana, entre elas, a literatura, na qual muitos autores e poetas descrevem suas dores. Numa outra abordagem, o texto literário traduz a peculiaridade do processo de adoecimento, podendo possibilitar uma visão mais ampla do indivíduo, pois coloca a doença no contexto em que estão inseridas as múltiplas nuances da existência e dos valores humanos, com toda a poesia e emotividade que a manifestação artística propõe ${ }^{1}$.

Adoecer pode imprimir diversos significados ao indivíduo e à sua família. Além dos sintomas físicos, tristeza, medo, ansiedade e baixa autoestima emergem como importantes elementos de sofrimento. É comum ainda que, devido ao seu quadro de saúdedoença, o doente tenha sua autonomia limitada; ou seja, por conta da sua fragilidade física e psíquica, não seja capaz de tomar decisões sobre sua própria vida ou até mesmo de expressar seus desejos e vontades.

Nesse ínterim, o indivíduo agora doente torna-se paciente - termo este originado do latim patientem: o que sofre, o que padece; e também utilizado na gramática no sentido de passividade, o sujeito que sofre alguma ação (do verbo)². A partir de então, a sua rotina muda drasticamente, especialmente durante a hospitalização, em que seu nome frequentemente cede lugar a um número de leito e a sua história resume-se à história da moléstia atual.

Em meio às representações do adoecer, a despersonalização do paciente e de sua história está presente no cuidado, e é frequentemente abordada na literatura. Este fenômeno reflete a experiência de perda de identidade e anonimato, engendrados pela própria condição de vulnerabilidade do adoecimento e da hospitalização, na qual o indivíduo é colocado distante da sua família, do seu ambiente e cotidiano ${ }^{3}$.

É importante salientar que a assistência em saúde e o ato de cuidar de pessoas envolve uma relação interpessoal entre os profissionais de saúde e os pacientes, pautada pelo envolvimento, pela empatia e pela promoção do bem-estar. Contudo, começam a existir cada vez mais relatos de experiências e histórias de sujeitos que, quando recorrem aos serviços de saúde, sentem que o atendimento, o acolhimento e a própria relação com os profissionais de saúde são marcados pela distância, pelo desinteresse e pela desumanização, centrada na doença e não na pessoa ${ }^{4}$.

Essa gradativa despersonalização que usurpa a empatia, a atenção e o acolhimento humanizado, não só do indivíduo como paciente, mas, principalmente, como ser humano, remove a sua história, identidade e características que o fazem único e, notoriamente, incapaz de ser resumido em uma patologia. Tal displicência no atendimento provoca a perda dessa face identificável e, por conseguinte, transporta sua existência subordinada a condição de número, leito e doença analisada.

\section{Desenvolvimento}

A despersonalização do indivíduo parece um caminho inexorável em que os elementos da sua existência e identidade são apagados com vistas a destacar um novo protagonista, que é a patologia que o acomete. Este fenômeno é brilhantemente retratado por Graciliano Ramos no conto Paulo (1985), em que a percepção de um doente hospitalizado é narrada em primeira pessoa, entretanto o mesmo não tem nome, nem a sua esposa. À sua doença ele dá o nome Paulo e, ao longo do texto, expõe sua angústia sobre não ser escutado ou compreendido naquele ambiente ${ }^{5}$.

Cabe salientar que identidade (ou identificação), aqui vista sob a perspectiva de Hall, pode ser lida como uma "narrativa do eu", constituída de valores, experiências e representações acumuladas pelo sujeito pós-moderno, construída historicamente a partir do viés cultural, e que supostamente desenha a existência dos seres humanos na sociedade ${ }^{6}$. A cisão entre pessoa e doente, portanto, nega ao sujeito a sua história e a singularidade da sua existência.

Segundo Angerami-Camoň, a despersonalização do paciente decorre também da fragmentação de olhares cada vez mais especializados que não se conversam de forma interdisciplinar. Diagnósticos cada vez mais específicos, que não alcançam uma visão holística do ser humano, não abordam a pessoa em sua amplitude existencial, simplificando a vida como um emaranhado de sintomas ou uma "lista de problemas". 


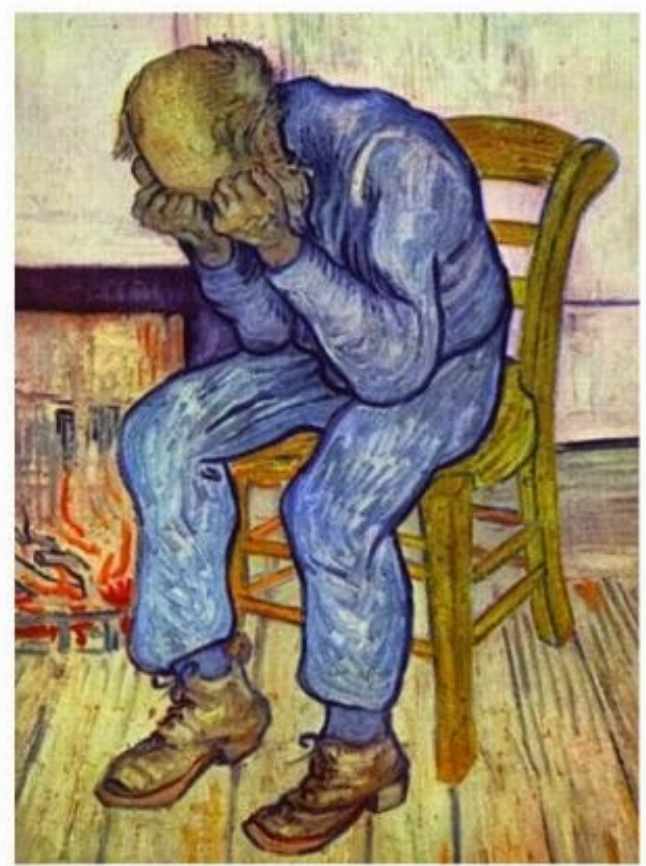

Van Gogh - Velho Entristecido, 1890

Em Velho Entristecido (1890), Van Gogh retrata a perda de identidade do paciente diante de um atendimento profissional distante emocionalmente, sem empatia e por muitas vezes desumanizado. A tristeza também é um reflexo resultante dessa desarmonia na relação médico-paciente, bem como a despersonalização caracterizada pela desvalorização da história e perspectivas do indivíduo acometido em atendimento ${ }^{\text {. }}$

Outro ponto relevante a ser analisado é o impacto da Síndrome de Burnout como condicionante da desumanização dos cuidados de saúde, em que os profissionais se encontram cansados e esgotados física e emocionalmente devido à natureza do trabalho e à forte estimulação emocional que está inerente ao desempenho das suas funções. Ademais, a omissão da humanidade do paciente é, involuntariamente, um mecanismo de defesa do cuidador ao desgaste emocional, uma vez que o distanciamento pode poupá-lo do envolvimento e do sofrimento?

São conhecidos de forma aprofundada os fatores de risco multidimensionais que aumentam a probabilidade de aparecimento do Burnout, assim como estão já identificadas as consequências da síndrome na vida do profissional, sublinhando-se os problemas físicos, mentais e psicológicos, o impacto na vida social e familiar do profissional e até a influência negativa no desempenho das suas funções, que, por sua vez, impacta negativamente a organização ${ }^{10}$.

Nesse sentido, é possível associar ainda o cenário de pandemia pela Covid-19 com um contexto que propicia o processo de despersonalização do paciente hospitalizado, principalmente quando se consideram as vivências dos indivíduos em unidades lotadas, assistindo a experiências de sofrimento físico e psicológico de outros pacientes. Há, portanto, perda de identidade em meio a uma coletividade. Além disso, a comunicação efetiva, principal viabilizador da autonomia do paciente e as interações desses pacientes com seus familiares, é dificultada por questões de segurança sanitária. Por outro lado, a falta de treinamento dos profissionais para lidar com situações que exigem comunicações sobre agravamento de doença e morte podem aumentar o risco de Burnout ${ }^{11}$.

Dessa forma, torna-se necessário o estabelecimento, quando possível, de meios de interação, ainda que virtuais, para médicos e pacientes, associado a um cuidado ainda maior para uma relação médico-paciente que ultrapasse o impessoal, estabelecida tanto pelas narrativas, quanto do olhar e da escuta. 
O processo de despersonalização do paciente e de sua história ainda está imbricado à prática médica e é estabelecido em muitas situações do cuidado que abrangem não só a aplicação da técnica, mas também a relação médico-paciente, assim como todas as vivências inerentes ao ser humano. Nesse sentido, é impossível falar sobre humanização da assistência em saúde sem destacar a necessidade de se ter uma visão holística e multidimensional do ser, em detrimento da abordagem focada na doença.

A narrativa literária, ao retratar o adoecimento e hospitalização, traz toda a subjetividade, incita reflexões e, por vezes, representa a voz daqueles que não são ouvidos e compreendidos. Assim, as artes literárias, aplicadas às ciências médicas, têm o potencial de estimular o resgate da identidade do indivíduo sob a condição de paciente, valorizar a escuta atenciosa do indivíduo e assim conferi-lo autonomia e cuidado.

\section{Agradecimentos}

Agradecemos às professoras leda Maria Barbosa Aleluia, Maristela Rodrigues Sestelo, Nelma Arônia Santos por todos os ensinamentos sem a qual a construção deste ensaio não seria possível, agradecemos também à Universidade do Estado da Bahia pela oportunidade e espaço de aprendizado.

\section{Contribuições dos autores}

Macedo AN, Bispo BHR e Santos DL contribuíram igualmente na aquisição, análise de dados, elaboração e redação do manuscrito.

\section{Conflitos de interesses}

Nenhum conflito financeiro, legal ou político envolvendo terceiros (governo, empresas e fundações privadas, etc.) foi declarado para nenhum aspecto do trabalho submetido (incluindo, mas não se limitando a subvenções e financiamentos, participação em conselho consultivo, desenho de estudo, preparação de manuscrito, análise estatística, etc.).
1. Scliar M. Literatura e medicina: o território partilhado. Cad Saúde Pública. 2000;16(1):245-8. https://doi.org/10.1590/S0102311X2000000100026

2. Dicionário Etimológico. Etimologia [Internet]. 7 graus; 20082020. [citado em 2020 set. 13]. Disponível em: https://www. dicionarioetimologico.com.br/

3. Imanishi H, Silva LL. Despersonalização nos hospitais: o estádio do espelho como operador teórico. Rev. SBPH [Internet]. 2016;19(1):41-56. Disponível em: http://pepsic.bvsalud.org/scielo. php?script=sci_arttext\&pid=S1516-08582016000100004

4. Fajardo R, Gonçalvez D, Lopes M, Rezende M, Zavanelli A. Acolhimento e bem estar no atendimento odontológico humanizado: o papel da empatia. Arch Health Invest [Internet]. 2015;4(3): 57-61. Disponível em: http://revodonto.bvsalud.org/ scielo.php?script=sci_arttext \&pid=S1516-09392012000300005

5. Ramos G. Insônia. 20a. ed. São Paulo: Record; 1985. p. 51-60.

6. Hall S. A identidade cultural na pós-modernidade. 11a. ed. Rio de Janeiro: DP\&A; 2011.

7. Angeramin-Camon VA, organizador. Psicologia Hospitalar: teoria e prática. 2a. ed. São Paulo: Cengage Learning; 2009

8. Borges G. Obras de Van Gogh para compreender melhor o pintor holandês [Internet]. eBiografia [atualizado em 2020 nov. 18; citado em 2020 ago. 12]. Disponível em: https://www. ebiografia.com/breve_biografia_van_gogh_obras/

9. Silva T, Foger D, Santos P. Despersonalização do paciente oncológico hospitalizado: uma revisão integrativa. Rev. Psic., Saúde \& Doenças. 2019;20(3): 651-8. http://dx.doi. org/10.15309/19psd200308

10. Carvalho CG, Magalhães SR. Síndrome de Burnout e as suas consequências nos profissionais de enfermagem. Rev Univ Vale do Rio Verde. 2011;9(1):200-10. http://dx.doi.org/10.5892/ RUVRV.91.200210

11. Crispim D, Silva MJP, Cedotti W, Câmara M, Gomes SA. Comunicação difícil e Covid19: Recomendações práticas para comunicação e acolhimento em diferentes cenários da pandemia [internet]. 2020 [citado em 2020 ago. 13]. Disponível em: https://ammg.org.br/wp-content/uploads/ comunica\%C3\%A7\%C3\%A3o-COVID-19.pdf.pdf 